\title{
Post rheumatic tricuspid valve disease associated to a left atrial mass in a young female: a case report
}

\begin{abstract}
Primary lesions of the tricuspid valve are rare. Tricuspid disease is an uncommon valvular abnormality that most commonly occurs in association with other valvular lesions, particularly in patients with rheumatic heart disease. For many years, surgical commissurotomy and valvuloplasty were the only available methods to correct tricuspid disease. We present a case of post rheumatic disease of the tricuspid valve in a young girl, associated to a left atrial mass.
\end{abstract}

Keywords: tricuspid valve, stenosis, girl
Volume I Issue 3 - 2017

Tantchou Tchoumi JC

St. Elizabeth Catholic General Hospital Shisong, Cardiac Centre, Cameroon

Correspondence: Tantchou Tchoumi Jacques Cabral, St. Elizabeth Catholic General Hospital, Cardiac Centre, Cardiologist, MD, PhD, Tel 237 699323742,

Email tantchouj@yahoo.fr

Received: June 19,2017 | Published: September 27, 2017

\section{Case report}

Miss $\mathrm{J}$ is an 18 years old young girl coming for the first time to consult in the Cardiac Centre Shisong presenting with shortness of breath on mild exertion, cough, abdominal swelling and mild lower limbs swelling. She was referred by a general practitioner who heard a murmur. In the history she agreed repetitive tonsillitis with fever and joint pains. Also has been regular to the dentist for teeth problems.

On physical examination she was very ill looking, afebrile, no pallor, mild peripheral cyanosis, good orientation in time and space. S1S2 were regular with a systolic murmur $2 / 6$ and diastolic murmur $3 / 6$ at the tricuspid area, a systolic murmur $2 / 6$ at the mitral area. The lungs were clear with good entry bilaterally, soft abdomen, not tender mild hepatomegly, lower limbs with mild pitting oedema.

\section{The cardiac echocardiography showed}

Dilated inferior vena cava- $18 \mathrm{~mm}$, dilated right atrium $87 * 63 \mathrm{~mm}$ with an area of $51,17 \mathrm{~cm}^{2}$ and a circumference of $27 \mathrm{~mm}$, the anterior and posterior leaflets were calcified and fused (Figure 1A), giving a severe stenosis with a peak gradient of $22,5 \mathrm{mmHg}$, the mean gradient was $9,9 \mathrm{mmHg}$, and pressure half time of $218 \mathrm{~ms}$ (Figure 1B). The tricuspid annulus was $57 \mathrm{~mm}$ (Figure 1D). The color continuous Doppler through the tricuspid valve gives also a mild regurgitation with a vena contracta- $8 \mathrm{~mm}$, we could see also the retraction of the subvalvular apparatus. The right ventricle is dilated but the systolic function was not compromised with a transannular annular plane systolic excursion-21mm. There was right ventricular systolic overload.

The left atrium $69 * 48 \mathrm{~mm}$ with an area of $26,7 \mathrm{~cm}^{2}$ and a circumference of $21 \mathrm{~mm}$ is having at the apex near the entrance of the inferior pulmonary veins a mass homogenous well organised looking like a myxoma having a circumference of $11,1 \mathrm{~mm}$, with a long axis of $44 \mathrm{~mm}$ and a short axis-18,5mm (Figure 1C). The mitral leaflets are mildly calcified with good function. The annulus is not dilated, $29 \mathrm{~mm}$. The left ventricle is not dilated with a paradoxal septum and acceptable systolic function. The laboratory analysis was within the normal limits: Rapid HIV testing was negative. WBC:4600cells $/ \mathrm{mm}^{3}$, a hemoglobin of $12.3 \mathrm{~g} / \mathrm{dL}$, Serum creat: $0,9 \mathrm{mg} / \mathrm{dl}, \mathrm{K}: 3 \mathrm{mmol} / 1$.
In the trans-oesophageal echocardiography, the mass was having the aspect of a myxoma. The patient could not afford the MRI. The patient was to undergo an open heart surgery with extracorporeal circulation for the plasty/replacement of the tricuspid valve and the excision of the mass and the confirmation of the diagnosis. Triscupid plasty was done successfully as well as the excision of the mass which had a benign etiology.

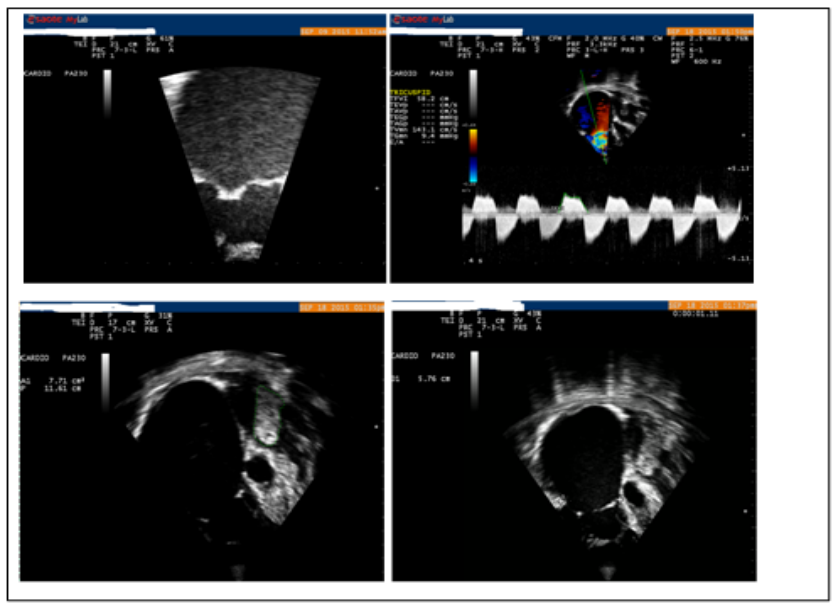

Figure I The echocardiogram of the patient.

A: Zoomed image of the fusion of tricuspid valve leaflets.

$B:$ Continuous Doppler through the tricuspid valve showing a peak gradient of $22,5 \mathrm{mmHg}$, the mean gradient was $9,9 \mathrm{mmHg}$, and pressure half time of $218 \mathrm{~ms}$. C: At the apex of the left atrium a mass having a circumference of $11,1 \mathrm{~mm}$, with a long axis of $44 \mathrm{~mm}$ and a short axis- $18,5 \mathrm{~mm}$.

D:Dilated right atrium $87 * 63 \mathrm{~mm}$ with an area of $51,17 \mathrm{~cm}^{2}$ and a circumference of $27 \mathrm{~mm}$, the tricuspid annulus having a dimension of $57 \mathrm{~mm}$.

\section{Discussion}

Tricuspid disease, most of which is of rheumatic origin, is rarely seen in developed countries, although it is still found in developing countries. The majority of cases of tricuspid rheumatic disease present with tricuspid regurgitation or a combination of regurgitation and stenosis. ${ }^{1,2}$ The case described above was a post rheumatic tricuspid 
valve disease, with calcified and fused tricuspid leaflets, restriction motion and retracted subvalvular apparatus. Other causes of obstruction to right atrial emptying are unusual and include congenital tricuspid atresia, right atrial tumors, which can produce a clinical picture suggesting rapidly progressive TS and carcinoid syndrome. ${ }^{3}$ Tricuspid disease and mainly stenosis has been also described in some cases due to lead endocarditis. It can be a chronic complication of pacemaker implantation that may occur more often than it is clinically suspected and may become even more common due to the growing number of cardiac devices currently implanted. The diagnosis should always be considered in patients with right heart failure and electrodes present in the right heart chambers. ${ }^{4,5}$ Surgical correction was the treatment of choice for pulmonary stenosis until three decades ago, when balloon valvuloplasty was implemented; nevertheless, percutaneous tricuspid valvuloplasty may be a therapeutic alternative to surgery in cases of TS alone without any concomitant valvulopathy. ${ }^{6,7}$ In our case surgical procedure was the procedure of choice since balloon valvuloplasty is not yet practices, with excision of the left atrial mass. Tricuspid plasty was done with good outcome as well as the excision of the mass which was benign.

Myxoma is the main differential diagnosis suggested for our patient as we know that this kind of tumor is located in $90 \%$ on left atrium. It is in general well circumscribed and has an ovular form. The magnetic resonance imaging has an important contribution in the differentiation of thrombus from myxoma. After gadolinium injection, myxoma is lifting up on periphery whereas thrombus remains unchanged. However, thrombus could also lift up on periphery when it is organized. ${ }^{9}$ The surgical procedure could be done in this case with a very good outcome, in contradistinction of the huge amount of cases with indication of open heart surgery that die because of financial limitations. This is the tip of the iceberg in countries with financial limitations where patients are poor and cannot afford open heart surgery. It urges our government and stakeholders to find sustainable solutions to save lives of citizens.

\section{Conclusion}

Tricuspid disease associated to left atrial mass is a rare entity. Surgical correction of the disease is the procedure of choice taking into consideration the clarification of the mass diagnosis.

\section{Acknowledgements}

None.

\section{Conflict of interest}

The author declares no conflict of interest.

\section{References}

1. Hauck AJ, Freeman DP, Ackermann DM, et al. Surgical pathology of the tricuspid valve: a study of 363 cases spanning 25 years. Mayo Clin Proc. 1988;63(9):851-863.

2. Daniels SJ, Mintz GS, Kotler MN. Rheumatic tricuspid valve disease: two-dimensional echocardiographic, hemodynamic, and angiographic correlations. Am J Cardiol. 1983;51(3):492-496.

3. Bonow R, Mann DL, Zipes DP, et al. Braunwald's heart disease: a textbook of cardiovascular medicine. 9th ed. Philadelphia: Elsevier Saunders; 2011. $2048 \mathrm{p}$.

4. Alves Ferreira ARP, Mendes SL, Martins R, et al. Unusual form of tricuspid stenosis. Int J Cardiovasc Sci. 2016;29(2):149-151.

5. Ribeiro H, Magalhães P, Ferreira C, et al. Pacemaker lead-induced tricuspid stenosis: a report of two cases. Rev Port Cardiol. 2012;31(4):305-308.

6. Nielsen EA, Hjortdal VE. Surgically treated pulmonary stenosis: over 50 years of follow-up. Cardiol Young. 2015;26(5):860-866.

7. Rama-Merchan JC, Arribas-Jimenez A, et al. Pacemaker lead-related tricuspid stenosis successfully treated with percutaneous balloon valvuloplasty guided by 3D echocardiography. Rev Port Cardiol. 2014;33(11):739-743.

8. Hwang JJ, Chen JJ, Lin SC, et al. Diagnostic accuracy of transesophageal echocardiography for detecting left atrial thrombi in patients with rheumatic heart disease having undergone mitral valve operations. Am J Cardiol. 1993;72(9):677-881.

9. Kim DH, Choi SI, Choi JA, et al. Various findings of cardiac thrombi on MDCT and MRI. J Comput Assist Tomogr. 2006;30(4):572-577. 